\title{
The Effect of Quarry Dust Concrete and Underlying Sub-Soil Medium on the Structural Performance of Dwelling House Ground Floors
}

\author{
Stanley Mbosha Denge ${ }^{1}$, W.Oyawa ${ }^{2}$, C.K.Kabubo ${ }^{3}$ \\ ${ }^{1}$ Sustainable Materials Research And Technology Centre, JKUAT, Kenya Kenya \\ ${ }^{2}$ Civil Engineering Department at JKUAT,Kenya \\ ${ }^{3}$ Sustainable Materials Research And Technology Centre, JKUAT, Kenya
}

\begin{abstract}
This research studied the effect of quarry dust concrete and the underlying subsoil medium on structural performance of dwelling houses ground floors. The volcanic rock aggregates used were graded $20 \mathrm{~mm}$ and 5-14mm, non-graded quarry dust and Nairobi sedimentary rock as well river sand and red soil . All were subjected to physical properties tests before use and soil further tested for unconfined compression and compaction.Concrete slabs (1:3:6)cement:sand:aggregates of one metre squared in thickness of 150 and $100 \mathrm{~mm}$, for the various aggregates were cast, cured for 28 days and tested over the soil compacted to maximum dry density by loading on jacks for compression and strain on their surfaces measured through strain gauges attached to a data logger. The $20 \mathrm{~mm}, 5-14 \mathrm{~mm}$, non-graded quarry dust and Nairobi sedimentary rock dust crushed at (3.3,3.2,2.2,2.1) Kn/m2 for $150 \mathrm{~mm}$ and $(2.9,2.8,1.2,0.8) \mathrm{Kn} / \mathrm{m} 2$ for $100 \mathrm{~mm}$ respectively. The $150 \mathrm{~mm}$ thick for all aggregates and only graded 100mm aggregate slabs crushed above allowable imposed design load $1.5 \mathrm{Kn} / \mathrm{m} 2$ for dwelling floors. The soil(sandy silty clay) when optimally compacted can safely transmit the loads of a dwelling house floor for graded aggregates from 100mm thick but for non graded the thickness has to be minimum $150 \mathrm{~mm}$.
\end{abstract}

Keywords: quarry dust concrete, underlying subsoil medium, compression, volcanic rock aggregates.

\section{Introduction}

The construction industry has received on-going criticism for its lack of innovation (Miozzo,et.al 2004; Drejer,2006) and numerous authors have expounded the specific challenges of innovating in the context of the built environment (Blayse et.al,2004; Dewick et.al, 2004). One of the unique challenges of innovation in construction is that novel solutions are typically not adopted within organisations, but in the context of one-off projects (Dewick et.al, 2002).

A building concrete ground floor bed can be said to be a concrete slab resting on and supported by the subsoil usually forming the ground floor surface. Concrete slabs (sometimes called over site concrete) are usually cast on a layer of hard-core which is used to make up the reduced level excavation and thus raise the level of the concrete bed to a position above ground level.

Mass concrete in ratio of $(1: 3: 6 / 20 \mathrm{~mm} \operatorname{mix} 15 \mathrm{~N} / \mathrm{mm} 2)$ is recommended (Chudley,2001) . Thickness for domestic ground floor slabs varies from $100 \mathrm{~mm}$ to $150 \mathrm{~mm}$ and the bed is constructed so as to prevent the passage of moisture from the ground to the upper surface of the floor. This is usually achieved by incorporating into the design a damp proof membrane. Providing the structural requirement of transmission of loads to the ground is the other function of a ground floor slab. Concrete in the above mix is composed of cement particles, aggregates and water (Chidiac et.al, 2009).

This study sought to design the slab by substituting the mass concrete with a quarry dust concrete and laying it on stable compacted subsoil to raise the level of the slab rather than the hardcore filling, of course incorporating the damp-proof membrane, checking whether this can still meet the structural and functional requirements of a floor.

\section{1the Floor Slab}

\section{Literature Review}

Concrete floor slabs are the most commonly used for both suspended and ground floors. This may be informed by their versatility, availability and as well cost considerations because there are other types such as suspended ground timber floors, and steel sheet floors which are not commonly used. Flooring for ground floors in dwelling housing is normally done in mass concrete ratio of $(1: 3: 6 / 20 \mathrm{~mm}$ mix $15 \mathrm{~N} / \mathrm{mm} 2)$ is recommended (Chudley et.al ,2001). Thickness for domestic work is usually $100 \mathrm{~mm}$ to $150 \mathrm{~mm}$ and the bed is constructed so as to prevent the passage of moisture from the ground to the upper surface of the floor, this is usually achieved 
by incorporating into the design a damp proof membrane .Concrete in the above mix is composed of cement particles, aggregates and water( Chidiacet.al, 2009).

Concrete slab floors come in many forms and can be used to provide great thermal comfort and lifestyle advantages. Slabs can be on-ground, suspended, or a mix of both. They can be insulated, both underneath and on the edges. Conventional concrete has high embodied energy. It has been the most common material used in slabs but several new materials are available with dramatically reduced ecological impact

\subsubsection{TYPES OF CONCRETE SLABS}

Concrete slabs can be on ground, suspended or precast

\subsubsection{BENEFITS OF CONCRETE FLOOR SLABS}

Amongst the benefits of concrete slabs are durability, thermal comfort and termite resistance( Chudley et.al 2001).

\subsubsection{FUNCTIONS OF CONCRETE SLABS}

The function of the bed in a floor as seen is mainly to support both live and dead loads as well as protect the surface of the floor from rising moisture. Live loading in a domestic house are relatively low and the dead loading from walls and roof are most of the time transmitted to the foundation through foundation walls. Moisture rise is caused by the floor being permeable and this is influenced by the aggregates because if the aggregate has a very low permeability, its presence reduces the effective area over which flow can take place. Because the flow path has to circumvent the aggregate particles, the effective path becomes considerably longer so that the effect of the aggregate in reducing the permeability may be considerable.

\subsubsection{THE AGGREGATES}

It is well known that mechanical and permeability properties of concretes are influenced by the watercement ratio, the cement-aggregate ratio, the bond between mortar and aggregate, and the grading, shape, strength, and size of the aggregates (Neville,2011).Aggregate particles influence the microstructure of the cement paste surrounding them( Bentur, 2000). The zone of cement paste that is affected by the aggregate particle has been defined as the interfacial transition zone (ITZ). Moreover, most of the important properties of hardened concrete are related to the quantity and characteristics of various types of pores in the cement paste and aggregate components of the concrete. For example, the engineering properties of concrete such as strength, durability, shrinkage, and transport, are directly influenced or controlled by the number, type, and size of pores present (Scrivener et.al 1996).

Mustafa,2010), in a study on the influence of the aggregate size on the mechanical and transport properties of concrete and concrete-equivalent mortars found out that compressive and split tensile strengths of concrete and CEMs (concrete-equivalent mortars) increased as the maximum aggregate size increased. The rate of increment was very little between the concrete produced with 22.4 and $16 \mathrm{~mm}$ maximum aggregate sizes. The same situation was valid for the CEMs produced with maximum aggregate sizes of 8 and $4 \mathrm{~mm}$.

\subsubsection{THE SUB-SOIL}

Floor beds are placed on reduced level subsoil's and it is well known that subsoil behave differently under loading depending with type, physical properties and the bearing capacity of each subsoil. Investigations undertaken in Dallas District in America on observed cracks on jointed concrete pavement (JCP), some of which had occurred on recently reconstructed JCP revealed that the base and the foundation soils had very poor compaction hence poor support to the concrete slab (Daret.al, 2007).

\subsection{MATERIAL PROPERTIES.}

\section{Materials And Methods}

The tables 1 and 2 below summarizes the properties of the materials used in the research(RS-river sand),(GQDgraded quarry dust),(NGQD-non graded quarry dust),(NSRD-nairobi sedimentary rock dust)and (CAconventional aggregates). The aggregates grading based on BS 882-1992 on grading of coarse aggregates and the soil on universal soil classification system (USCS). All the aggregates were well graded while the soil was established as a sandy silty CLAY with traces of gravel.

Table1: Specific Gravity and Water Absorption for the various aggregates

\begin{tabular}{|l|l|l|l|l|l|}
\hline & RS & GQD & NGQD & NRSD & CA \\
\hline Specific gravity on oven dry basis & 2.45 & 2.56 & 2.42 & 2.4 & 2.55 \\
\hline $\begin{array}{l}\text { Specific gravity on saturated surface } \\
\text { dry(SSD) basis }\end{array}$ & 2.52 & 2.44 & 2.53 & 2.50 & 2.45 \\
\hline Apparent specific gravity & 2.46 & 2.60 & 2.44 & 2.42 & 2.61 \\
\hline Water absorption\% & 0.23 & 0.1 & 0.26 & 0.27 & 0.94 \\
\hline
\end{tabular}


The effect of quarry dust concrete and underlying sub-soil medium on the structural performance of ..

Table 2. Summary of Test Soil Properties

\begin{tabular}{|l|l|}
\hline Specific gravity & 2.526 \\
\hline Liquid limit & 48.8 \\
\hline Plastic limit & 30.4 \\
\hline Linear shrinkage & 12.3 \\
\hline Plastic index & 18.4 \\
\hline Soil classification(USCS)-plasticity & CL \\
\hline Soil classification by particle size & Sandy Silty CLAY with traces of Gravel \\
\hline Normal stress $\left(\mathrm{kgk} / \mathrm{cm}^{2}\right)$ & 0.773 \\
\hline Dry density, $\left(\mathrm{g} / \mathrm{cm}^{3}\right)$ & 0.128 \\
\hline Compressive strain, $\varepsilon(\%)$ & 2.275 \\
\hline Shear stress, q $\left(\mathrm{kgf} / \mathrm{cm}^{2}\right)$ & 0.387 \\
\hline Maximum Dry Density $\mathrm{g} / \mathrm{cm}^{3}$ & 1.347 \\
\hline $\begin{array}{l}\text { Optimum Moisture Content } \\
\text { (compaction) }\end{array}$ & $23.4 \%$ \\
\hline
\end{tabular}

\section{Results And Discussion}

After crushing the concrete slabs of 150 and $100 \mathrm{~mm}$ thickness over compacted soil,the results were graphically represented for stress against strain as shown in figures 3 and four below.

Fig.1.stress /strain relationship forcrushing of $150 \mathrm{~mm}$ concrete slabs.

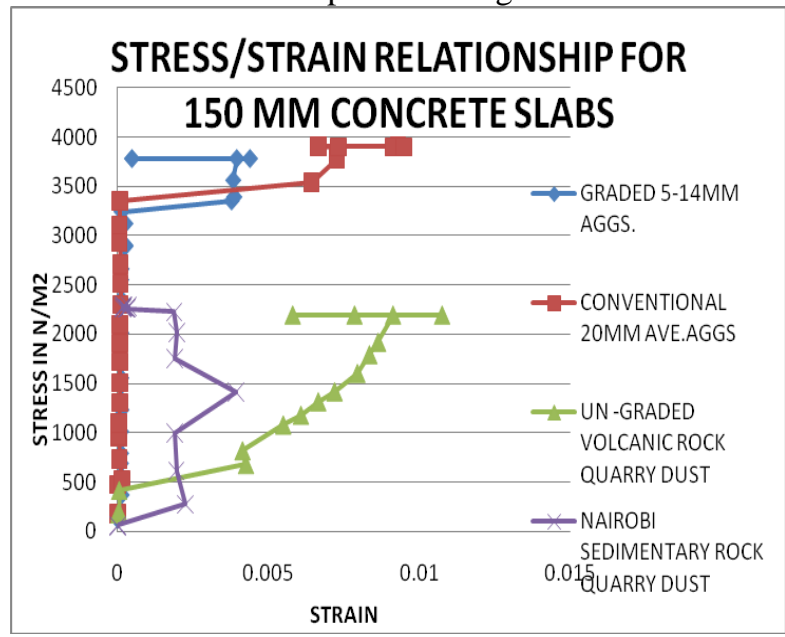

Fig 2. stress /strain relationship forcrushing of 100mm concrete slabs.

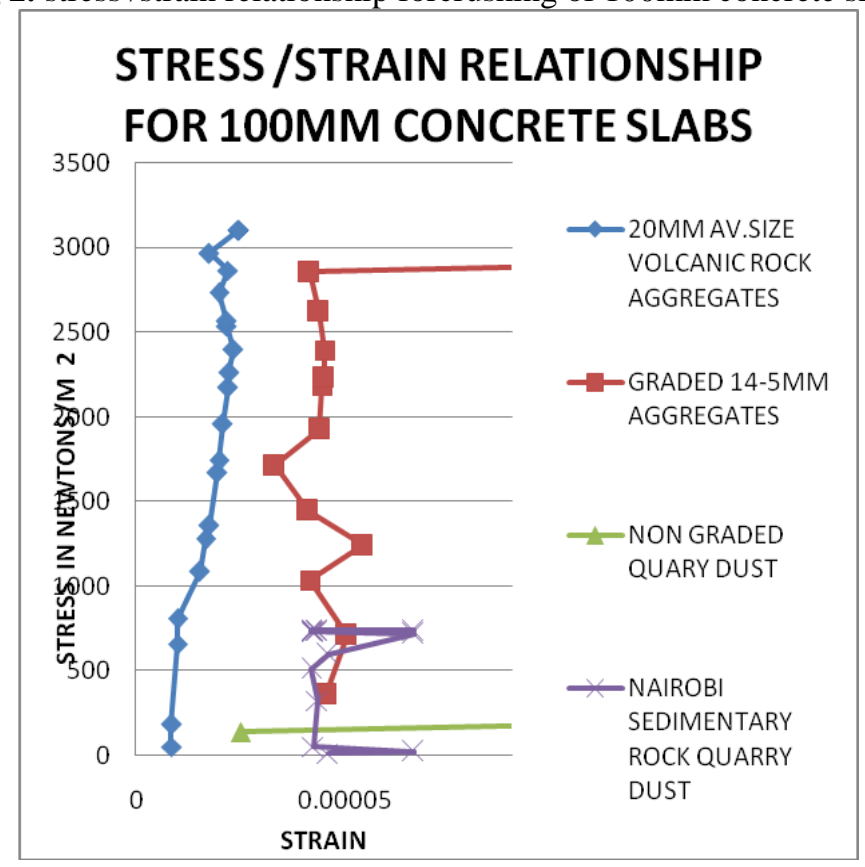


The effect of quarry dust concrete and underlying sub-soil medium on the structural performance of ..

Loading at failure compared to optimum allowable loads was tabulated in table 3 below.

From table 12and figures 1 and 2 above it can be seen that all the $150 \mathrm{~mm}$ slabs crushed at above $1.5 \mathrm{kn} / \mathrm{m}$ minimum allowable imposed loads as per BS6399-1.The slabs of 100mm thick had two of them crushing below $1.5 \mathrm{kn} / \mathrm{m}$

From the stress graphs the loading increased until the samples could not take any more loads meaning the sample had given way. From the stress/strain graphs fig.1 and 2 for both $150 \mathrm{~mm}$ and $100 \mathrm{~mm}$ concrete slabs it can be seen that there is so much strain in quarry dust concretes and as well they crushed at lower stress than the conventional $20 \mathrm{~mm}$ aggregates which is a proof from a study by (Mustafa et.al ,2010). In the study, the influence of the aggregate size on the mechanical and transport properties of concrete and concrete-equivalent mortars which found out that Compressive and split tensile strengths of concrete and CEMs (concreteequivalent mortars) increased as the maximum aggregate size increased.

Table 3: Loadings at Failure for various aggregate slabs in different thickness crushed over a compacted subsoil medium.

\begin{tabular}{|l|l|l|l|}
\hline & $\begin{array}{l}150 \mathrm{~mm} \text { slabs imposed } \\
\text { load failure in KN/m2 }\end{array}$ & $\begin{array}{l}100 \mathrm{~mm} \text { slabs } \\
\text { imposed load failure in KN/m2 }\end{array}$ & $\begin{array}{l}\text { maximum allowable design } \\
\text { loads for domestic floors }\end{array}$ \\
\hline 20mm volcanic rock aggs. & 3.3 & 2.9 & 1.5 \\
\hline graded 5-14mm volcanic rock aggs & 3.2 & 2.8 & 1.5 \\
\hline non graded volcanic rock quarry dust & 2.2 & 1.2 & 1.5 \\
\hline Nairobi sedimentary rock quarry dust & 2.1 & 0.8 & 1.5 \\
\hline
\end{tabular}

Concrete cubes were also cast, cured for 28 days and their strengths tested in compression. all crushed above the $15 \mathrm{~N} / \mathrm{mm} 2$ characteristic compressive strength as per BS6399-1 at 28 days and only the Nairobi sedimentary stone dust concrete cube crushed below this. Compressive strength results are summarized in the table below

Table4. Results of concrete compressive strength and young's modulus

\begin{tabular}{|l|l|l|l|}
\hline & $\begin{array}{l}\text { 150mm slabs Characteristic } \\
\text { compressive strength N/mm2 at 28 } \\
\text { days(class 15 concrete) }\end{array}$ & $\begin{array}{l}\text { 100mm slabs Characteristic } \\
\text { compressive strength(N/mm } 2 \text { )at 28 } \\
\text { days(class 15 concrete) }\end{array}$ & $\begin{array}{l}\text { Young's } \\
\text { modulus(GPa) }\end{array}$ \\
\hline 20mm volcanic rock aggs. & 20 & 15 & 26.6 \\
\hline Graded 5-14mm volcanic rock aggs & 19 & 15 & 16 \\
\hline Non graded volcanic rock quarry dust & 16 & 15 & 3.6 \\
\hline Nairobi sedimentary rock quarry dust & 14 & 15 & 1.4 \\
\hline
\end{tabular}

\subsection{WATER SEEPAGE TEST}

Another aspect of the test was the rate of water flow through the sample which attempted to define permeability. This had all the concrete comparing fairly for the 28 days they were subjected to the test. The larger aggregates had better resistance to water flow than the smaller size aggregates. further proof in research by (Mustafa et.al ,2010), that Water sorptivity values of concrete and CEMs increased while decreasing the maximum aggregate size. The test results are demonstrated in the figure 3 . below

Figure3 .water seepage in concrete

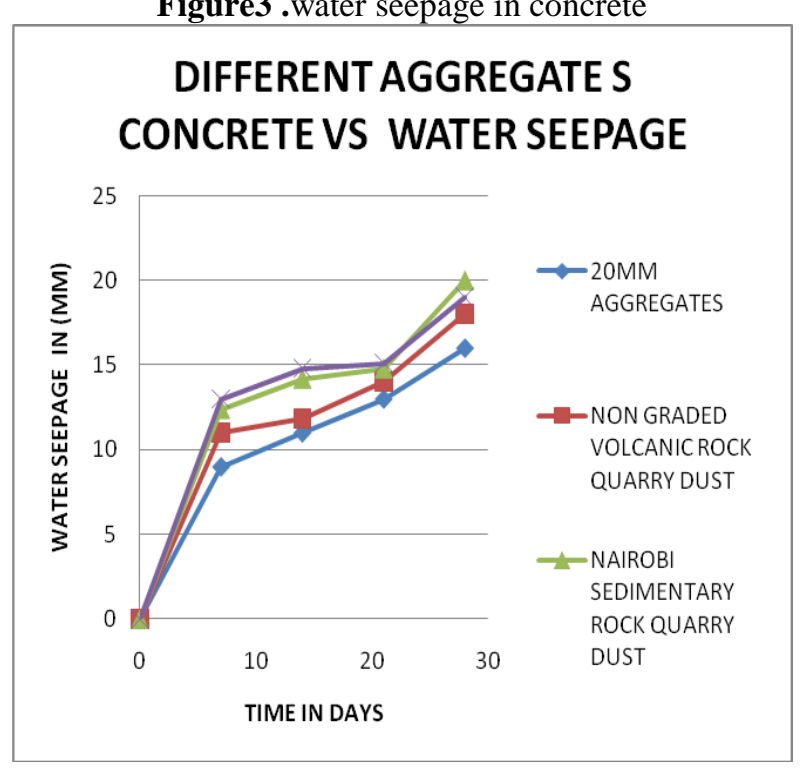


The specific conclusions made from the study

\section{Conclusions}

1. Depths of quarry dust concrete slab affects the structural soundness and engineering properties of a ground floor slab. Smaller depths less than $150 \mathrm{~mm}$ of non graded quarry dust concrete slabs cannot meet the structural requirements of a ground floor slab, has to be $150 \mathrm{~mm}$ and above in thickness. Graded aggregates of quarry dust from 5-20mm used as coarse aggregates meets the structural soundness of a concrete ground floor slab.

2. The larger the coarse aggregate in ground floor concrete slabs, the more is the concrete able to withstand compressive strength and water percolation. Concretes made in non graded quarry dust can only marginally meet allowable compressive strengths but as from $5 \mathrm{~mm}$ to $20 \mathrm{~mm}$ graded aggregates when used in concrete the values for compressive strength are higher and as well they do not allow in much water seepage as the smaller sized aggregates.

3. Natural sub base like granular soils when optimally compacted will safely transmit loads to the ground without necessarily needing to replace them with hard core. Unless there are ground water issues which could be arrested with other methods such as incorporating of a damp proof membrane natural sub base of granular soils of at least red soil can meet functional requirements of a ground floor slab.

\section{Recommendations}

Consequently, it is further recommended that:

1. There is need for a further research on various soils so as to provide a better guide on sub-soils strengths for the floors for this research only tested the Juja red soil.

2. It will also be important to test the subsoil in this research when stabilized to compare how it would behave.

3. Further research should be done for the quarry dust concrete on suspended reinforced slabs.

\section{References}

[1]. Blayse A.M,K.Manley, (2004).key Influences On Construction Innovation, Construction Innovation vol.4 isi 3,pp.143-154

[2]. ChidiacS.E.AndF.mahmoodzadeh,2009,"plastic viscosity of fresh concrete - a critical review of predictions methods," cement and concrete composites vol.31pp 535-544

[3]. Chudley.R and R.greeno(2001) Building construction handbook, fourth edition

[4]. Dewick P, M Miozzo.(2002). Factors enabling and inhibiting sustainable technologies in construction: the case of active solar heating systems. International journal of innovation management;6(3):257-76.

[5]. Dewick.P and M.Miozzo(2004),networks and innovation,sustainable technologies in scotish social housing 34(3,323-33)

[6]. Drejer I, A.L Vinding.(2006) Organisation, 'anchoring' of knowledge, and innovative activity in construction. Construction management and economics;24(9):921-31.

[7]. Miozzo M. and P.Dewick,(2004).Networks and Innovation in European Construction. International Journal of technology management (1)68-92.

[8]. Mustafa Kemal University, Iskenderun, Hatay, Turkey,(2010) Influence of Aggregate Size on the Mechanical and Transport Properties of Concretes and Concrete-Equivalent mortars, Canadian Journal Of Civil Engineering, 2010, 37(10): 1303-1314, $10.1139 / 110-072$

[9]. R Bentur A,(2000)'The role of interfaces in controlling the durability of fibre reinforced cements', journal of materials in civil engineering., vol. 12, no.1, pp.2-7.

[10]. Scrivener, K.L., and P.L.Pratt(1996) "characterization of interfacial microstructure," in interfacial transition zone in concrete, ed. J.c. Maso (e \& fn spon, london, 3-17. 